\title{
Transmitted Drug Resistance in Hiv-1 Non-B Subtypes Newly Diagnosed Patient: Case Report
}

\author{
Brindicci G ${ }^{1 *}$, Cibelli DC ${ }^{2}$, Santoro $\mathrm{CR}^{1}$, Lepore $\mathrm{L}^{1}$, Lagioia $\mathrm{A}^{1}$, Monno $\mathrm{L}^{1}$ and Angarano $\mathrm{G}^{1}$ \\ ${ }^{1}$ Operative Unit of Infectious Diseases, Hospital-University Polyclinic - Paediatric Hospital “Giovanni XXIII”, Italy \\ ${ }^{2}$ Operative Unit of Infectous Diseases, "Santo Spirito" Hospital, Italy
}

Received date: October 02, 2018; Published date: November 30, 2018

*Corresponding author: Gaetano Brindicci, Operative Unit of Infectious Diseases, Hospital-University Polyclinic - Paediatric Hospital “Giovanni XXIII", Bari, Italy

\begin{abstract}
Antiretroviral therapy has a very high efficacy and has substantially changed patients' quality of life, although it does need an equallyhigh adherence. The widespread use of antiretroviral therapy has significantly reduced the risk of HIV. However, at the same time it has resulted in an increase in HIV-drug resistance, which can be transmitted to newly-infected individuals, thus compromising the efficacy of combination regimens and potentially leading to the their failure. In Europe the overall prevalence of transmitted HIV-drug resistance was 8.3\% in 2008-2010 and it is considered rather uncommon in non-B subtypes. In this study we report a case of drug-resistance transmission in a patient with HIV inter recombinant form infection. The transmission occurred heterosexually in a couple of immigrants without stay permit. Phylogenetic analysis was performed. Our report underlines how, even if not very high, the prevalence of HIV primary drug resistance is essential to perform the resistance test, at least of the pol gene in all new HIV diagnoses. Even in countries with high income and almost totalfree diagnosis and treatment, some patient settings are at risk of developing drug-resistant strains. More studies are needed for the proper evaluation of transmitted HIVDR in non-B subtypes of HIV.
\end{abstract}

Keywords: HIV drug resistance transmission; Transmitted HIVDR; CRFs

\section{Introduction}

Antiretroviral therapy (ART) has a very high efficacy and has substantially changed the quality of life of patients but needs an equally-high adherence [1]. The widespread use and increased coverage of ART has significantly reduced the risk of HIV transmission and decreased HIV-related morbidity and mortality [2]. At the same time, however, the greater availability of ART globally has determined and continues to determine the increase in resistant strains even in treatment-naive patients. The transmission of HIV drug-resistant strains has gradually become a concern because it has the potential to compromise the efficacy of combination ART regimens and may lead to the failure in firstline ART [3]. Patients who acquire or are primarily infected with HIV-1 drug-resistant viruses have fewer treatment options and are at increased risk of morbidity and mortality, particularly in developing countries where choices for ART are limited [4,5]. For this reason, the international organizations and guidelines of many countries recommend performing the pol gene-resistance test in all newly-diagnosed cases of HIV infection, despite being an expensive test and not available in the Pediatric centers [6-8].

Poor adherence is the main cause of drug resistance [9]. In high-income countries and ones in which the health system guarantees all expenses related to the diagnosis and treatment of HIV infection (such as Italy), adherence is lower in some categories of patients: immigrants (especially those without a regular residence permit), adolescents, patients with mental illness or addictions, patients with a lower cultural level $[10,11]$. The prevalence of transmitted HIV drug resistance (HIVDR) is highest in developed countries, estimated between $8.4 \%$ and $22.7 \%$ [12-18]. In a most recent European publication, where Italian data were included, a prevalence of TDR was of around 8\% was estimated [19] and in any case until 2012 this was closely associated with HIV-1 subtype B infection $[20,21]$. The most frequent indicators of TDR were nucleoside reverse-transcriptase inhibitors (NRTIs) mutations (4.5\%), followed by non-nucleoside reverse transcriptase inhibitors (NNRTIs) mutations (2.9\%) and protease inhibitors (PIs) mutations (2.0\%). Although TDR was highest for NRTIs, the impact of baseline drug-resistance patterns on susceptibility was largest for NNRTIs [20].

In this report we describe a case of primary transmission of drug resistance, occurred in a heterosexual couple of immigrants, lived in our country without a regular stay permit. The circulating recombinant form 02_AG (CRF02_AG) was involved. More precisely the strain was identified as an A1, G, CRF02_AG inter recombinant form, that grouped into CRF02_AG (when phylogenetic analysis was performed). According to the data present in the literature, non-B clades are less efficient in HIVDR and CRF02_AG is the least implicated subtype [20]. 


\section{Current Trends in Clinical \& Medical Imaging}

\section{Methods}

Genotyping of the predominant HIV population was performed with the Viroseq HIV Genotyping Kit (Applied Biosystems, Foster City, CA), and the HIV Genotyping System SoftwareTM was used for data analysis. Nucleotide sequences of the pol gene were submitted to the Sequence Analysis Program of the Stanford HIV RT and Protease Sequence Database [21] which furnishes a computer assisted interpretation of mutational profiles. The sequences were then analyzed for phylogenetic relationships. BioEdit [22] was used to align query sequences (D.A. and G.N.) with pure subtype and circulating recombinant form (CRF) reference sequences obtained from the Los Alamos database [23]. The subtype assignment of the non-clade B strains was confirmed by a bootstrapped phylogenetic analysis using SEQBOOT with 1,000 replicates, followed by the DNAdist (with Kimura 2-parameter method and a transition/transversion ratio of 2.0), Neighbor and Consense programs contained in PHYLIP (PHYLogeny Inference package) $[24,25]$. The strains were subsequently analyzed by Simplot software (version 2.5) [26] by boot scanning application to identify the subtypes involved in the recombination and their breakpoints. The phyogenetic relationships were visualized by application called Tree View [27].

\section{Case Report}

The case of a 32-year-old man coming from Guinea (D.A.). In October 2013 the patient had a HIV-1 infection diagnosis at a different Hospital in Apulia. He manifested generalized tonic-clonic seizures followed by an altered state of consciousness. The MRI brain scan was consistent with Toxoplasma gondii brain abscesses and a treatment with pyrimethamine and sulfadiazine was started. Also, daily efavirenz, emtricitabine and tenofovir therapy was begun, but the patient in the same data self-resigned and was lost to follow-up. The genotypic analyses of viral sequence had not been made. In January 2014 the patient manifested an altered state of consciousness and a left-side hemiparesis and he was admitted to the Bari Infectious Diseases Clinic in. The brain MRI confirmed multiple brain abscesses surrounded by a perilesional edema. The CD4+ count was 49 cells $/ \mathrm{mm}^{3}$ and the HIV- 1 plasma viral load was 1,950,000 copies/ml (RT-PCR). An anti-toxoplasma therapy was resumed.

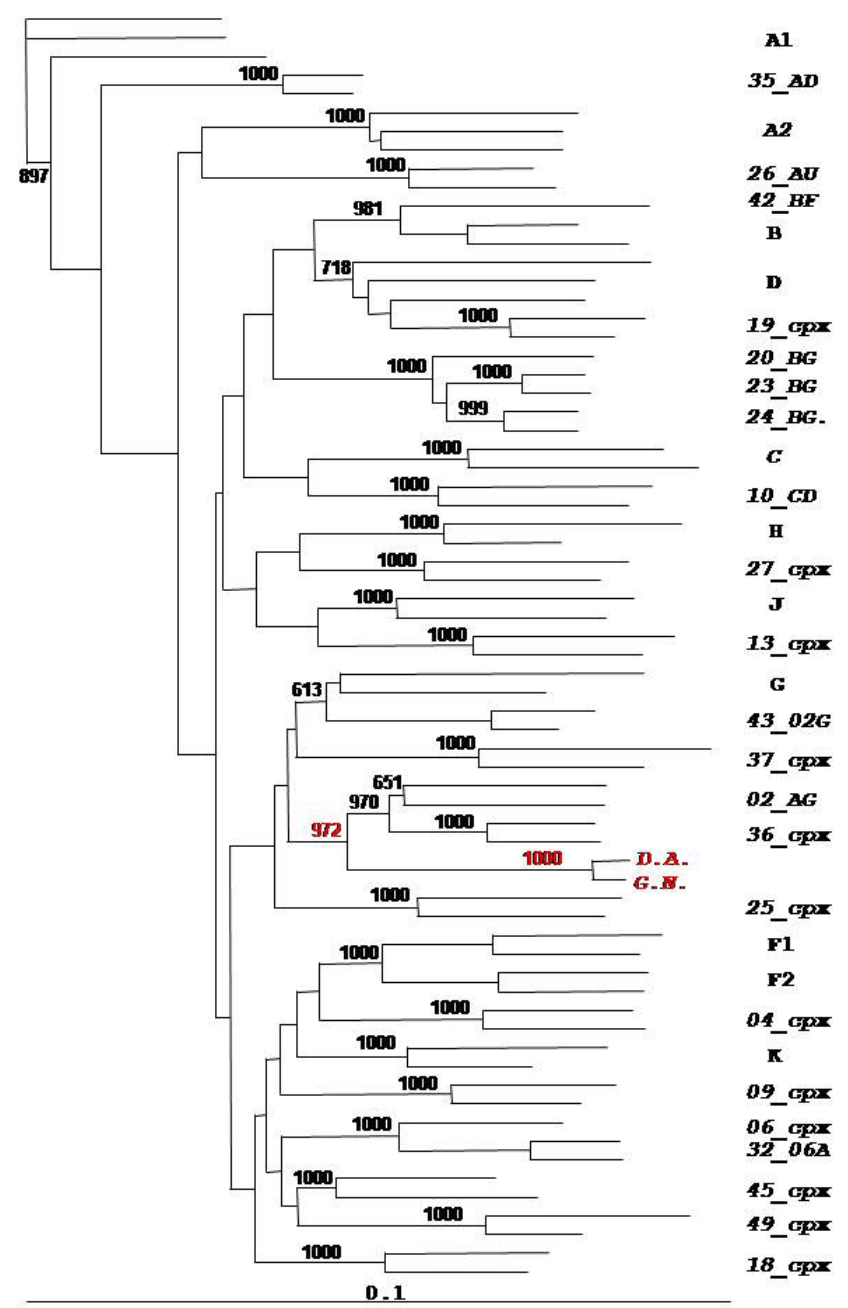

Figure 1: Phylogenetic neighbor-joining tree of pol gene (protease and reverse transcriptase domains) (nt. 2253-3221) sequences from our patients. Bootstrap values (1000 replicates) are indicated on the branch leading to the subtype. 


\section{Current Trends in Clinical \& Medical Imaging}

Genotypic-resistance testing on plasma and phylogenetic analysis by neighbour-joining (N) trees and boot-scanning software was performed. Phylogenetic analyses showed that the patients were infected with a complex recombinant form that involved clade A1, G and CRF02_AG. The breakpoints however were different respect on the and the other known $A / G$ interrecombinant forms (Figures $1 \& 2$ ). Primary-resistance mutations associated with NRTIs and NNRTIs were reported (Figure 3a). PIs primary resistance were absent. A new ART regimen was started with boosted lopinavir/emtricitabine/tenofovir and one month later CD4+ cells were $105 / \mathrm{mm}^{3}$ and HIV-1 plasma viral load was 3195 copies/ml. A follow-up MRI brain scan at the end of 6 weeks of treatment confirmed complete edema resolution. An improvement of patient's clinical condition was reported too. Moreover, the patient's partner from Georgia was tested and she was diagnosed with HIV-1 infection too. She was a naïve advanced subject; her CD4 count was 120 cells $/ \mathrm{mm}^{3}$ and HIV-1 plasma viral load was 98,000 copies/ml. The resistance profile showed the presence of three mutations responsible for drug-resistance to NNRTIs (also present in the partner): V90I, A98G, Y181C. The M184V mutation responsible for resistance to NRTIs was not transmitted (Figure 3b). Phylogenetic analyses revealed that the patient's partner was infected with the same recombinant form (Figure 3) never described in Georgian patients.

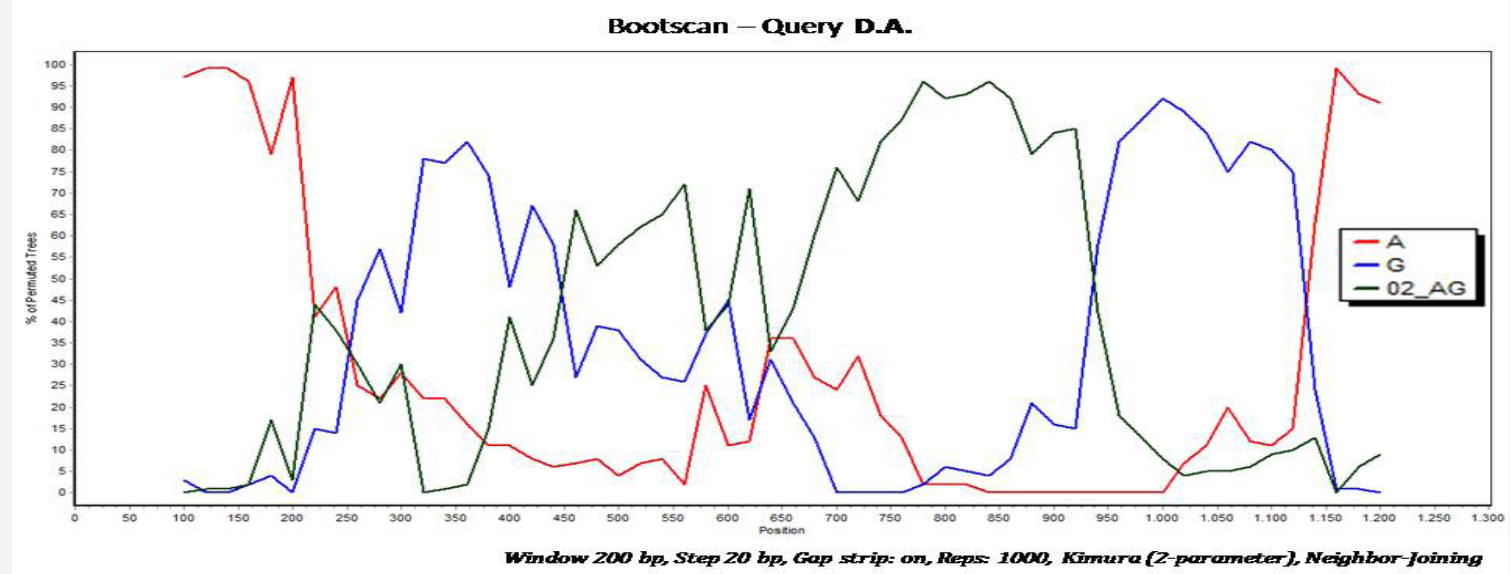

Figure 2: Bootscan analysis of D.A pol gene sequence. Boot scanning plot is performed with the Simplot program using $200 \mathrm{bp}$ window and step size of $20 \mathrm{bp}$. Breakpoint locations are based on the HXB2 numbering engine. Recombinants segments are indicated above the plot.

\begin{tabular}{|c|c|c|c|c|}
\hline \multicolumn{4}{|c|}{ Drug Resistance Interpretation: RT } & \multirow{2}{*}{ Patient D.A. } \\
\hline \multicolumn{4}{|c|}{ NRTI Resistance Mutations: M184I } & \\
\hline \multicolumn{4}{|c|}{ NNRTI Resistance Mutations: V9ol, } & \\
\hline \multicolumn{2}{|c|}{ Other Mutations: } & \multicolumn{3}{|c|}{$\begin{array}{l}\text { K20R, V35T, E36A, T39K, K43E, K122E, D123N, S162A, T165I, } \\
\text { K173T, Q174K, D177E, T200A, Q207E, D237N, V245Q, E248N, } \\
\text { D250E, E291D, V292I, I293V, P294T, I326V }\end{array}$} \\
\hline \multicolumn{3}{|c|}{ Nucleoside RTI } & \multicolumn{2}{|c|}{ Non-Nucleoside RTI } \\
\hline lamivudine (3TC) & \multicolumn{2}{|c|}{ High-level resistance } & efavirenz (EFV) & High-level resistance \\
\hline abacavir (ABC) & \multicolumn{2}{|c|}{ Low-level resistance } & etravirine (ETR) & High-level resistance \\
\hline zidovudine (AZT) & \multicolumn{2}{|c|}{ Susceptible } & nevirapine (NVP) & High-level resistance \\
\hline stavudine (D4T) & \multicolumn{2}{|c|}{ Susceptible } & rilpivirine (RPV) & High-level resistance \\
\hline didanosine (DDI) & \multicolumn{4}{|c|}{ Potential low-level resistance } \\
\hline \multirow{2}{*}{$\begin{array}{l}\text { emtricitabine (FTC) High-level resistance } \\
\text { tenofovir (TDF) }\end{array}$} & \multicolumn{4}{|c|}{ High-level resistance } \\
\hline & \multicolumn{4}{|c|}{ Susceptible } \\
\hline
\end{tabular}

\begin{tabular}{|c|c|c|c|c|}
\hline \multicolumn{4}{|c|}{ Drug Resistance Interpretation: RT } & \multirow{2}{*}{ Patient G.N. } \\
\hline \multirow{2}{*}{\multicolumn{2}{|c|}{$\begin{array}{l}\text { NRTI Resistance Mutations: } \\
\text { NNRTI Resistance Mutations: }\end{array}$}} & \multicolumn{2}{|c|}{ None } & \\
\hline & & \multicolumn{3}{|c|}{ V901, A98G, Y181C } \\
\hline \multicolumn{2}{|l|}{ Other Mutations: } & \multicolumn{3}{|c|}{$\begin{array}{l}\text { V35T, E36A, T39K, K43E, K122E, D123N, S162A, T165I, K173T, } \\
\text { Q174K, D177E, I178M, G196R, T200A, Q207E, R211KR, F214FL, } \\
\text { V245Q, E248N, D250E, E291D, V292I, I293V, P294T, I326V }\end{array}$} \\
\hline \multicolumn{3}{|c|}{ Nucleoside RTI } & \multicolumn{2}{|c|}{ Non-Nucleoside RTI } \\
\hline lamivudine (3TC) & \multicolumn{2}{|l|}{ Susceptible } & efavirenz (EFV) & Intermediate resistance \\
\hline abacavir $(A B C)$ & \multicolumn{2}{|l|}{ Susceptible } & etravirine (ETR) & Intermediate resistance \\
\hline zidovudine (AZT) & \multicolumn{2}{|l|}{ Susceptible } & nevirapine (NVP) & High-level resistance \\
\hline stavudine (D4T) & \multicolumn{2}{|l|}{ Susceptible } & rilpivirine (RPV) & Intermediate resistance \\
\hline didanosine (DDI) & \multicolumn{2}{|l|}{ Susceptible } & & \\
\hline \multicolumn{3}{|c|}{ emtricitabine (FTC) Susceptible } & & \\
\hline tenofovir (TDF) & \multicolumn{2}{|l|}{ Susceptible } & & $3 \mathbf{b}$ \\
\hline
\end{tabular}

Figure 3: Drug Resistance interpretation of retrotrascriptase of the two patients. 


\section{Discussion}

Our case report leads us to make different considerations. First of all, the primary transmission of resistance, although not common in high-income countries, can be a dangerous event, especially in those patients who have less access to the health system. Even in countries like Italy, where access to the diagnosis and treatment of infectious diseases, chronic diseases and maternal and child health is free and universally- guaranteed by law (even to those who do not have a regular permit to stay) there are particular settings of patients who can, for various reasons, have difficulty using health services. That is to say, indigent, elderly people with addictions, along with immigrants are our most vulnerable categories of people in our society. As far as HIV infection is concerned, we would above all like to point out repeatedly that among migrants there is a greater number of diagnoses in late stages of the disease, a faster progression of the disease, a lower percentage of retention in care, but also a lower perception of being taken care of by the health system. Moreover, our cases are original because they occurred in a clade considered not to be very involved in the transmission of drug resistance. Larger-scale studies should be conducted on the implications of the subtype on drug resistance transduction. It is possible that this varies from clade to clade and therefore it is important to study each one individually. It is more than probable that with the increase in non-B subtypes and CFRs in high-income countries that have been reported for years in all of Europe, even cases of resistance transmitted in non-B subtypes will increase. Lastly, it is further confirmed that the genotypic test is fundamental before starting ART therapy.

\section{Acknowledgment}

We would just like to dott. James Hart's proof-reading and translation checking.

\section{Conflicts of Interest}

None.

\section{References}

1. The HIV CAUSAL Collaboration, Ray M, Logan R, Sterne JA, HernándezDíaz S, et al. (2010) The effect of combined antiretroviral therapy on the overall mortality of HIV-infected individuals. Aids 24(1): 123-137.

2. Lima VD, Harrigan R, Bangsberg DR, Hogg RS, Gross R, et al. (2009) The Combined Effect of Modern Highly Active Antiretroviral Therapy Regimens and Adherence on Mortality Over Time. JAIDS 50(5): 529536.

3. Booth CL, Geretti AM (2007) Prevalence and determinants of transmitted antiretroviral drug resistance in HIV-1 infection. I Antimicrob Chemother 59(6): 1047-1056.

4. Hogg RS, Bangsberg DR, Lima VD, Alexander C, Bonner S, et al. (2006) Emergence of drug resistance is associated with an increased risk of death among patients first starting HAART. PLoS Med 3(9): e356.

5. Palella FJ Jr, Armon C, Buchacz K, Cole SR, Chmiel JS, et al. (2009) The association of HIV susceptibility testing with survival among HIV infected patients receiving antiretroviral therapy: a cohort study. Ann Intern Med 151(2): 73-84.

6. European AIDS Clinical Society (2015) EACS guidelines version 8.0.
7. Gunthard HF, Aberg JA, Eron JJ, Hoy JF, Telenti A et al. (2014). Antiretroviral treatment of adult HIV infection: 2014 recommendations of the International Antiviral Society-USA Panel. JAMA 312(4): 410425.

8. Wensing AM, Calvez V, Gunthard HF, Johnson VA, Paredes R, et al. (2014) Update of the drug resistance mutations in HIV-1. Top Antivir Med 22(3): 642-650.

9. Emamzadeh-Fard S, Fard SE, Seyed Alinaghi S, Paydary K (2012) Adherence to anti-retroviral therapy and its determinants in HIV/AIDS patients: a review. Infect Disord Drug Targets 12(5): 346-356.

10. Saracino A, Tartaglia A, Trillo G, Muschitiello C, Bellacosa C, et al. (2014) Late presentation and loss to follow-up of immigrants newly diagnosed with HIV in the HAART era. J Immigr Minor Health 16(4): 751-755.

11. Saracino A, El-Hamad I, Prato R, Cibelli DC, Tartaglia A, et al. (2005) Access to HAART in HIV-infected immigrants: a retrospective multicenter Italian study. AIDS Patient Care STDS 19(9): 599-606.

12. Little SJ, Holte S, Routy JP, Daar ES, Markowitz M, et al. (2002) Antiretroviral-Drug Resistance among Patients Recently Infected with HIV. N Engl J Med 347: 385-394.

13. Grant RM, Hecht FM, Warmerdam M, Liu L, Liegler T, et al. (2002) Time Trends in Primary HIV-1 Drug Resistance among Recently Infected Persons. JAMA 288(2): 181-188.

14. Wensing AM, van de Vijver DA, Angarano G, Asjö B, Balotta C, et al. (2005) Prevalence of Drug-Resistant HIV-1 Variants in Untreated Individuals in Europe: Implications for Clinical Management. J Infect Dis 192(6): 958-966.

15. Vercauteren J, Wensing AM, Van de Vijver DA, Albert J, Balotta C, et al. (2009) Transmission of Drug-Resistant HIV-1 is Stabilizing in Europe. J Infect Dis 200(10): 1503-1508.

16. Little SJ, May S, Hecht F, Markowitz M, Daar ES, et al. (2006) Increase in transmitted NNRTI drug resistance among recently HIV infected patients from North America and Australia. Antivir Ther 11 Suppl 1: S110.

17. Dai L, Mahajan SD, Sykes DL, Shon A, Schwartz S, et al. (2014) Prevalence of Transmitted HIV-1 Drug Resistance (TDR) Associated Mutations and Predicted Drug Sensitivity in Newly Diagnosed HIV-1 Patient Cohort in a Western New York, 2005-2011. J Antivir Antiretrovir 6: 022-027.

18. Ross LL, Florance A, Wine B, Craig C, Vavro C, et al. (2007) Prevalence of HIV-1 drug resistance-associated mutations in a large cohort of antiretroviral therapy (ART) naïve HIV-infected individuals in the United States from 2000-2004. Antivir Ther 11 Suppl 1: S120.

19. Marije Hofstra LM, Sauvageot N, Albert J, Alexiev I, Garcia F, et al (2016) Transmission of HIV Drug Resistance and the Predicted Effect on Current First-line Regimens in Europe. Clin Infect Dis 62(5): 655663.

20. Franzetti M, Lai A, Simonetti FR, Bozzi G, De Luca A, et al. (2012) High burden of transmitted HIV-1 drug resistance in Italian patients carrying F1 subtype. J Antimicrob Chemother 67(5): 1250-1253.

21. http://hivdb.stanford.edu/hiv/

22. http://www.mbio.ncsu.edu/BioEdit/bioedit.html.

23. http://hivweb.lanl.gov/

24. http://evolution.genetics.washington.edu/phylip.html

25. Felsenstein J (1996) PHYLIP: Phylogeny Inference Package. Version 3.52 Seattle, (WA): University of Washington, USA.

26. Ray SC (1998) SimPlot for Windows (version 1.6). Baltimore Md.

27. Page RD (1996) TreeView: an application to display phylogenetic trees on personal computers. Comput Appl Biosci 12(4): 357-358. 
Your next submission with Juniper Publishers will reach you the below assets

- Quality Editorial service

- Swift Peer Review

- Reprints availability

- E-prints Service

- Manuscript Podcast for convenient understanding

- Global attainment for your research

- Manuscript accessibility in different formats ( Pdf, E-pub, Full Text, Audio)

- Unceasing customer service

Track the below URL for one-step submission https://juniperpublishers.com/online-submission.php 